\title{
Space Vector PWM for Three Series-Connected Permanent Magnet Synchronous Motors Drive System
}

\author{
ZHANG Hua-qiang $^{1, a}$, LU Xiao-tong ${ }^{1, b}$, WANG Xin-sheng ${ }^{1, c}$, WANG Xue-yi ${ }^{2, d}$ \\ and LENG Yan-li ${ }^{2, e}$
}

${ }^{1}$ Department of Electrical Engineering, Harbin Institute of Technology at Weihai, Weihai, Shandong, China

${ }^{2}$ Huanghai Ship Building co.,LTD, Rongcheng, Shandong, China

azhq@hit.edu.cn, blulu_5412@163.com, cwangxswh@126.com

djipints@126.com, ehuanghai7035@126.com

Keywords: space vector PWM; series-connected three-motor; dual three-phase; two-phase; permanent magnet synchronous motor.

\begin{abstract}
Since multiphase machines have more additional degree of freedom than three-phase machine, which can be utilized to control other machines, a number of machines can be controlled independently. The stator windings of the machines can be series connected by an appropriate phase transposition, with the supply coming from a single multiphase inverter. This paper proposed a novel series-connected system, composed of two dual three-phase permanent magnet synchronous motors (PMSMs), one two-phase PMSM and a seven-phase voltage source inverter (VSI) and controlled using space vector PWM. In such a way, independent control of the three series-connected PMSMs is achieved. The simulation results indicated that three machines can operate independently while taking three different loads, supplied from the same seven-phase inverter.
\end{abstract}

\section{Introduction}

The study of the multiphase machine drive appeared in 1969. With the development of multiphase machines technology, multiphase machines are widely used in marine electric propulsion, railway traction, electric vehicle traction and more-electric aircraft [1]. Multiphase machine has the advantages of high torque density, small torque ripple, higher ripple frequency, less current harmonic of DC bus, high efficiency, fault tolerance and reliability, compared with the three-phase machine.

Dual three-phase PMSM as a kind of multiphase machine is used frequently at present, the main advantages of PMSM are wide speed range and high energy conversion efficiency. To compare with the three-phase machine, dual three-phase machine can eliminate the 5th and 7th harmonic magnetic potential which have the most impact on the performance, reduce the torque ripple greatly and improve the machine performance [2].

Series-connected multi-motor system is mainly applied to the subway, ship propulsion, locomotive traction, extrusion unit, robot and heavy electrical applications. Previous studies indicate multiphase machines can be series connected by an appropriate phase transposition and fed from a single VSI. A symmetrical six-phase machine can be connected in series with a three-phase machine [3]. The research of series-connected five-phase two-motor system has been elaborated in [6-10], as well as the series-connected seven-phase three-motor system [11]. What is more, the realization of the series-connected system is applicable not only to symmetrical but also to asymmetrical multiphase machines. Two asymmetrical six-phase machines (dual three-phase machines) can be series-connected by an appropriate phase transposition, supplied from the same inverter.

This paper presents a novel topology, a series-connected two dual three-phase and two-phase three-motor drive system and proceeds as follow. Section 2 presents the drive system structure and section 3 performs the mathematical analysis on the space vector decoupling. Section 4 discusses the SVPWM technology in series-connected three-motor system, while the simulation results and conclusions of the study are summarized in Section 5 and 6. 


\section{Three Series-Connected PMSMs Drive Structure}

The three series-connected PMSMs drive system supplied from a seven-phase VSI has four orthogonal components in a seven dimensional space. However, only two components are needed for field oriented (component with 90 degree phase shift). Thus, in this three-motor system, three orthogonal pairs are available to realize three field oriented controllers. To achieve the decoupling control of three machines, the stator windings of three machines need to be connected in series by a proper phase transposition. The connection diagram is given in Fig. 1. As two-phase with spatial displacement of 90 degree between the phases, the current or voltage of neutral point is not zero applied the Y connection. Thus, add one bridge arm in the inverter and connect the neutral point of two-phase machine to the midpoint of this bridge arm, on which the duty cycle of the switching device should be $50 \%$.

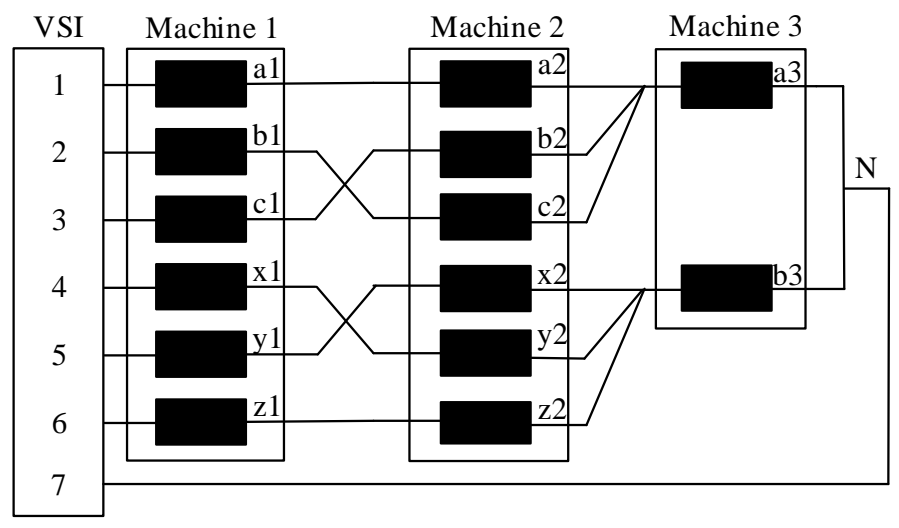

Figure 1. Three series connected PMSMs system.

According to clarke's decoupling transformation matrix for a symmetrical n-phase system, the decoupling transformation matrix for an asymmetrical six-phase system can also be derived as Eq. 1. The phase variables can be transferred to power invariant form of three-motor system by this decoupling transformation matrix.

$$
\boldsymbol{T}_{6 s / 2 s}=\frac{1}{\sqrt{3}}\left[\begin{array}{ccccccc}
1 & \cos \frac{2 \pi}{3} & \cos \frac{4 \pi}{3} & \cos \frac{\pi}{6} & \cos \frac{5 \pi}{6} & \cos \frac{3 \pi}{2} \\
0 & \sin \frac{2 \pi}{3} & \sin \frac{4 \pi}{3} & \sin \frac{\pi}{6} & \sin \frac{5 \pi}{6} & \sin \frac{3 \pi}{2} \\
1 & \cos \frac{4 \pi}{3} & \cos \frac{2 \pi}{3} & \cos \frac{5 \pi}{6} & \cos \frac{\pi}{6} & \cos \frac{3 \pi}{2} \\
0 & \sin \frac{4 \pi}{3} & \sin \frac{2 \pi}{3} & \sin \frac{5 \pi}{6} & \sin \frac{\pi}{6} & \sin \frac{3 \pi}{2} \\
1 & 1 & 1 & 0 & 0 & 0 \\
0 & 0 & 0 & 1 & 1 & 1
\end{array}\right] .
$$

\section{Space Vector PWM for the Three-Motor System}

The Selection of the Space Vectors. A switching function $S_{i} \in\{1,0\}$ is defined for each seven-phase inverter leg, $i=1,2 \ldots 7$. The inverter output phase-to-neutral voltages are performed as functions of the switching function $S_{i}$. And the phase voltage space vectors can be defined for $\alpha-\beta, z_{1}-z_{2}$ and $o_{1}-O_{2}$ planes as functions of the inverter output phase-to-neutral voltages: 


$$
\begin{aligned}
& u_{\alpha_{1} \beta_{1}}=u_{\alpha_{1}}+j u_{\beta_{1}}=\frac{1}{3} U_{d c}\left(u_{a 1}+u_{b 1} e^{j 4 \alpha}+\mathrm{u}_{c 1} e^{j 8 \alpha}+\mathrm{u}_{x 1} e^{j \alpha}+\mathrm{u}_{y 1} e^{j 5 \alpha}+\mathrm{u}_{z 1} e^{j 9 \alpha}\right) . \\
& u_{z_{1} z_{2}}=u_{z_{1}}+j u_{z_{2}}=\frac{1}{3} U_{d c}\left(u_{a 1}+u_{b 1} e^{j 8 \alpha}+\mathrm{u}_{c 1} e^{j 4 \alpha}+\mathrm{u}_{x 1} e^{j 5 \alpha}+\mathrm{u}_{y 1} e^{j \alpha}+\mathrm{u}_{z 1} e^{j 9 \alpha}\right) . \\
& u_{o_{1} o_{2}}=u_{o_{1}}+j u_{o_{2}}=U_{d c}\left(u_{a 2}+u_{b 2} e^{j 3 \alpha}\right) .
\end{aligned}
$$

Generally, an n-phase two-level VSI is characterized with $2^{\mathrm{n}}$ voltage space vectors. Thus, for a dual three-phase PMSM there are $2^{6}=64$ space vectors, four of which are zero vector; for a two-phase PMSM there are $2^{3}=8$ space vectors, two of which are zero vectors. All the space vectors of three planes are easily calculated using Eq. 2, Eq. 3 and Eq. 4. The seven-phase VSI voltage space vectors of the three plane are shown in Fig. 2.

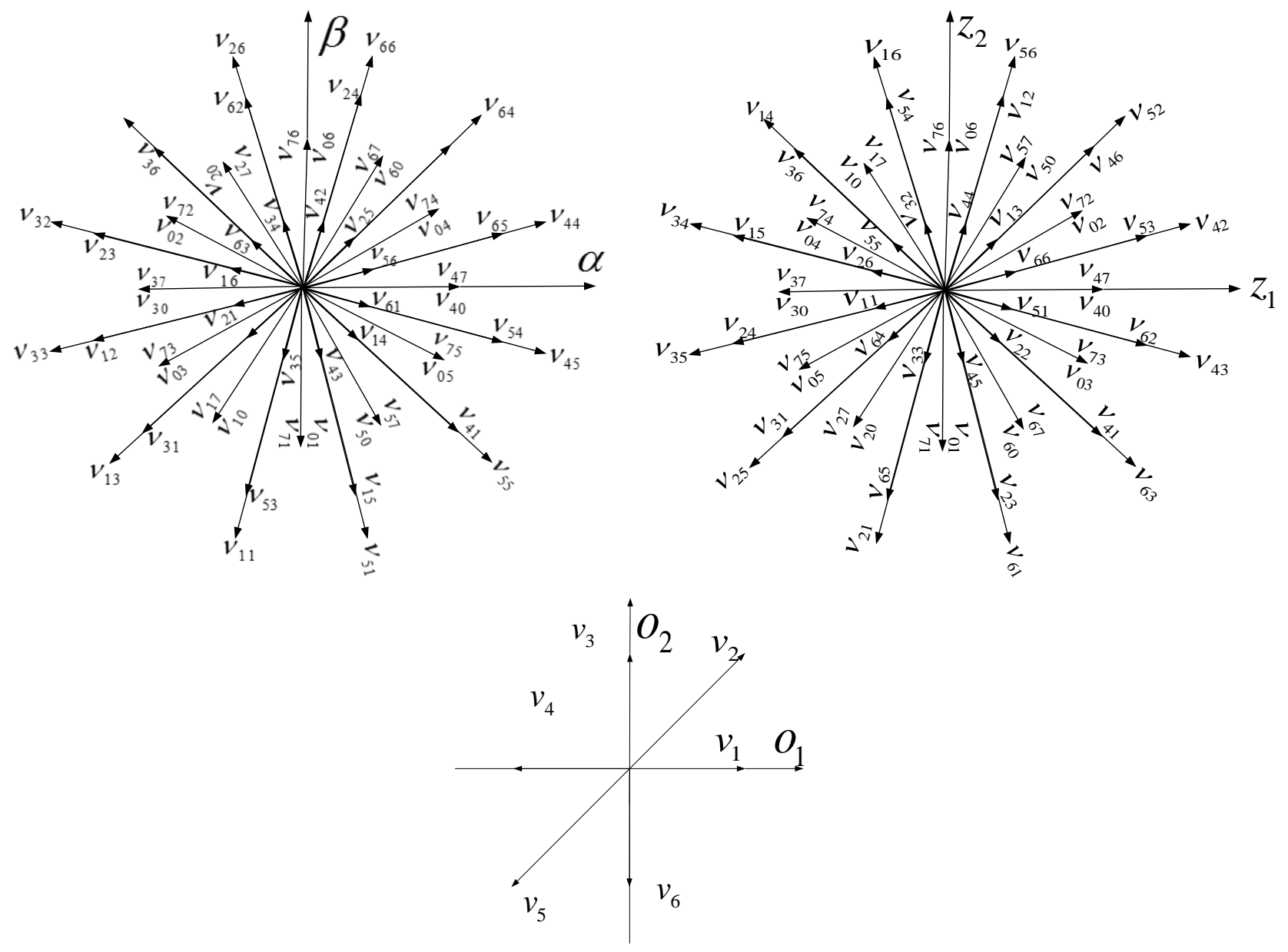

Figure 2. Seven-phase VSI phase voltage space vectors in $\alpha-\beta, z_{1}-z_{2}$ and $o_{1}-o_{2}$ planes.

The Calculation of the Space Vectors Acting Time. According to the necessary conditions that the selected vectors must satisfy, for two dual three-phase machines, select the largest four neighboring non-zero vectors in each sector of $\alpha-\beta$ and $z_{1}-z_{2}$ plane from Fig. 2 to synthesize the reference voltage vector, the amplitude value of which is $0.644 \mathrm{U}_{\mathrm{dc}}$. And for two-phase machine, select two non-zero vectors in each sector of $o_{1}-O_{2}$ plane from Fig. 2 is enough, the amplitude of which is $U_{d c}$ or $1.414 U_{d c}$.

According to the projection relationship between the reference voltage vectors and the selected voltage vectors in $\alpha-\beta$ and $z_{1}-z_{2}$ reference frames, the following matrix is obtained. 


$$
\left[\begin{array}{c}
u_{\alpha} T_{s} \\
u_{\beta} T_{s} \\
u_{\mathrm{z}_{1}} T_{s} \\
u_{\mathrm{z}_{2}} T_{s}
\end{array}\right]=\left[\begin{array}{cccc}
u_{1 \alpha} & u_{2 \alpha} & u_{3 \alpha} & u_{4 \alpha} \\
u_{1 \beta} & u_{2 \beta} & u_{3 \beta} & u_{4 \beta} \\
u_{1 \mathrm{z}_{1}} & u_{2 \mathrm{z}_{1}} & u_{3 \mathrm{z}_{1}} & u_{4 \mathrm{z}_{1}} \\
u_{1 \mathrm{z}_{2}} & u_{2 \mathrm{z}_{2}} & u_{3 \mathrm{z}_{2}} & u_{4 \mathrm{z}_{2}}
\end{array}\right]\left[\begin{array}{c}
T_{1} \\
T_{2} \\
T_{3} \\
T_{4}
\end{array}\right]
$$

After simplifying, the application times for both sets of four active space vectors are

$$
\left[\begin{array}{c}
T_{1} \\
T_{2} \\
T_{3} \\
T_{4}
\end{array}\right]=\frac{T_{s}}{2 U_{d c}}\left[\begin{array}{cccc}
2 \sqrt{3}-3 & -\sqrt{3} & -2 \sqrt{3}-3 & \sqrt{3} \\
3-\sqrt{3} & -3+\sqrt{3} & 3+\sqrt{3} & -3-\sqrt{3} \\
3-\sqrt{3} & 3-\sqrt{3} & 3+\sqrt{3} & 3+\sqrt{3} \\
2 \sqrt{3}-3 & \sqrt{3} & -2 \sqrt{3}-3 & -\sqrt{3}
\end{array}\right]\left[\begin{array}{l}
u_{\alpha} \\
u_{\beta} \\
u_{z_{1}} \\
u_{z_{2}}
\end{array}\right] .
$$

The definition of the modulation index $m$ is the ratio of the phase voltage fundamental peak value and a half of the DC bus voltage. For the SVPWM strategy, linear modulation range can reach the inscribe cycle of dodecagon formed by the twelve biggest space voltage vectors, so the maximum value of the reference voltage vector is $0.622 U_{d c}$, thus $m=1.244$.

According to the projection relationship between the reference voltage vectors and the basic voltage vectors in sector I , the following matrix is obtained.

$$
\begin{aligned}
& u_{1} \boldsymbol{T}_{1}^{\prime}+u_{2} \boldsymbol{T}_{2}^{\prime}=u_{s} \boldsymbol{T}_{s} . \\
& U_{d c} T_{1}^{\prime}+U_{d c} T_{2}^{\prime}=u_{o_{1}} T_{s} . \\
& U_{d c} T_{2}^{\prime}=u_{o_{2}} T_{s} \\
& T_{1}^{\prime}=\frac{u_{o_{1}}-u_{o_{2}}}{U_{d c}} T_{s} \quad T_{2}^{\prime}=\frac{u_{o_{2}}}{U_{d c}} T_{s} .
\end{aligned}
$$

Similarly, the application times of voltage vectors in every sector are obtained, shown in Table 1.

Table 1: The voltage vector action times in each sector of two-phase PMSM

\begin{tabular}{lll}
\hline Sector & $\mathrm{T}_{1}{ }^{\prime}$ & $\mathrm{T}_{2}{ }^{\prime}$ \\
\hline I & $\left(\mathrm{U}_{\mathrm{O} 1}-\mathrm{U}_{\mathrm{O} 2}\right) \mathrm{T}_{\mathrm{s}} / \mathrm{U}_{\mathrm{dc}}$ & $\mathrm{U}_{\mathrm{O} 2} \mathrm{~T}_{\mathrm{s}} / \mathrm{U}_{\mathrm{dc}}$ \\
II & $\mathrm{U}_{\mathrm{O} 1} \mathrm{~T}_{\mathrm{s}} / \mathrm{U}_{\mathrm{dc}}$ & $\left(\mathrm{U}_{\mathrm{O} 2}-\mathrm{U}_{\mathrm{O} 1}\right) \mathrm{T}_{\mathrm{s}} / \mathrm{U}_{\mathrm{dc}}$ \\
III & $-\mathrm{U}_{\mathrm{O} 1} \mathrm{~T}_{\mathrm{s}} / \mathrm{U}_{\mathrm{dc}}$ & $\mathrm{U}_{\mathrm{O} 2} \mathrm{~T}_{\mathrm{s}} / \mathrm{U}_{\mathrm{dc}}$ \\
IV & $\left(\mathrm{U}_{\mathrm{O} 2}-\mathrm{U}_{\mathrm{O} 1}\right) \mathrm{T}_{\mathrm{s}} / \mathrm{U}_{\mathrm{dc}}$ & $-\mathrm{U}_{\mathrm{O} 2} \mathrm{~T}_{\mathrm{s}} / \mathrm{U}_{\mathrm{dc}}$ \\
$V$ & $-\mathrm{U}_{\mathrm{O} 1} \mathrm{~T}_{\mathrm{s}} / \mathrm{U}_{\mathrm{dc}}$ & $\left(\mathrm{U}_{\mathrm{O} 1}-\mathrm{U}_{\mathrm{O} 2}\right) \mathrm{T}_{\mathrm{s}} / \mathrm{U}_{\mathrm{dc}}$ \\
$V$ & $-\mathrm{U}_{\mathrm{O} 2} \mathrm{~T}_{\mathrm{s}} / \mathrm{U}_{\mathrm{dc}}$ & $\mathrm{U}_{\mathrm{O} 1} \mathrm{~T}_{\mathrm{s}} / \mathrm{U}_{\mathrm{dc}}$ \\
\hline
\end{tabular}

Due to the asymmetry of two-phase PMSM space voltage vectors distribution, the linear modulation range can reach the inscribe cycle of hexagon formed by the six space voltage vectors, and the maximum value of the reference voltage vector is $0.707 U_{d c}$, thus the modulation index $m=1.414$.

\section{Space Vector PWM for the Three-Motor System}

The simulation model of three series-connected PMSMs drive system is established in Matlab/Simulink, the parameters of two machines are shown in Table 2 and Table 3. 
Table 2: The parameter of dual three-phase PMSMs

\begin{tabular}{lll}
\hline Parameter name & Machine 1 & Machine 2 \\
\hline Stator resistance $[\Omega]$ & 2.875 & 2.875 \\
D-axis inductance [mH] & 8.5 & 12 \\
Q-axis inductance $[\mathrm{mH}]$ & 8.5 & 12 \\
Rotor flux [Wb] & 0.175 & 0.2 \\
Rotational inertia [kg•m2] & 0.089 & 0.1 \\
Pole pairs & 4 & 4 \\
Damping coefficient & 0.005 & 0.01 \\
\hline
\end{tabular}

Table 3: The parameter of two-phase PMSM

\begin{tabular}{ll}
\hline Parameter name & Machine 3 \\
\hline Stator resistance $[\Omega]$ & 6.31 \\
Rotor resistance $[\Omega]$ & 5.44 \\
Stator inductance [mH] & 383 \\
Rotor inductance [mH] & 373 \\
Rotor flux [Wb] & 0.51 \\
Rotational inertia [kg•m2] & 0.02 \\
Pole pairs & 2 \\
Damping coefficient & 0.001 \\
\hline
\end{tabular}

The simulation results are shown in Fig. 3 and Fig. 4.
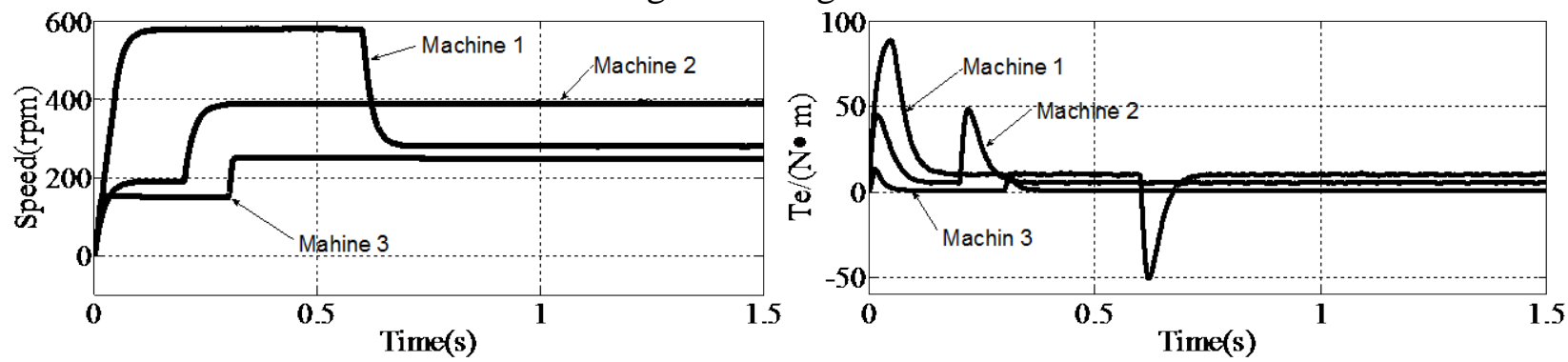

Figure 3. Speed and torque characteristic of three machines.
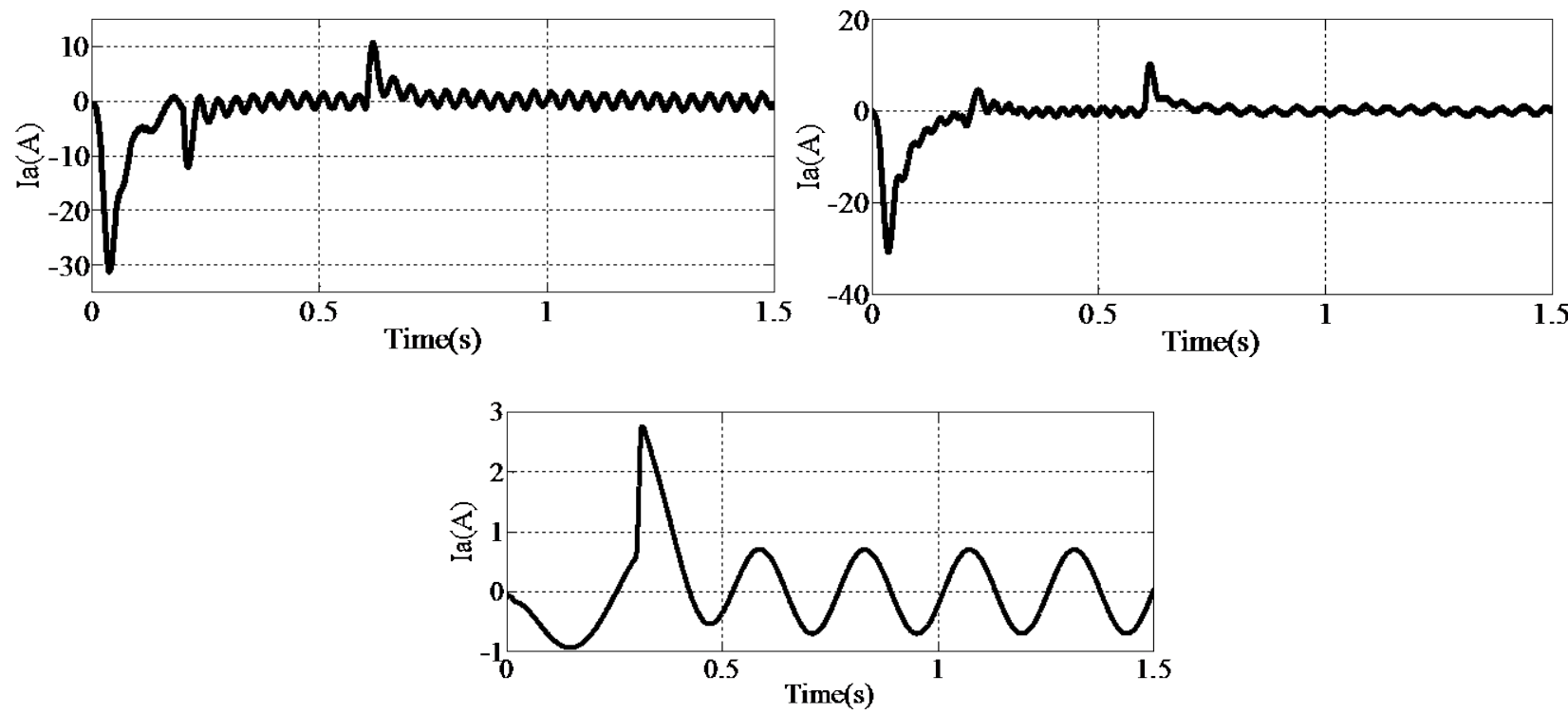

Figure 4. Stator phase 'a' current of machine 1, machine 2 and machine 3

\section{Summary}

This paper develops a novel mathematical model of a three series-connected PMSMs drive system using space vector decoupling and space vector PWM. The system is supplied by a single 
seven-phase VSI, which is fed to the stator using a proper phase transportation. Detailed analysis on SVPWM for the drive system is performed. The developed mathematical model is validated using Matlab/Simulink simulation approach, the results verify the three machines can operate independently without mutual influence while they take different loads.

\section{References}

[1] E. Levi, R. Bojoi, F. Profumo, H.A. Toliyat and S. Williamson, in: Multiphase Induction Motor Drives - A Technology Status Review, volume 1 of IET Electric Power Applications, chapter, 4, IET Publisher (2007).

[2] Zhao Yi-fan and T.A. Lipo, in: Space Vector PWM Control of Dual Three-Phase Induction Machine Using Vector Space Decomposition, volume 31 of IEEE Transactions on Industry Applications, chapter 5, IEEE Publisher (1995).

[3] E. Levi, M. Jones and N.V. Slobodan, in: A Series-Connected Two-Motor Six-Phase Drive with Induction and Permanent Magnet Machines, volume 21 of IEEE Transactions on Energy Conversion, chapter 1, IEEE Publisher (2006).

[4] D. Dujic, G. Grandi, M. Jones and E. Levi, in: A Space Vector PWM Scheme for Multifrequency Output Voltage Generation with Multiphase Voltage-Source Inverters, volume 55 of IEEE Transactions on Industrial Electronics, chapter, 5, IEEE Publisher (2008).

[5] E. Levi, S.N. Vukosavic and M. Jones, in: Vector Control Schemes for Series-Connected Six-Phase Two-Motor Drive Systems, volume 152 of IEE Proceedings - Electric Power Applications, chapter, 2, IET Publisher (2005).

[6] A. Iqbal and Levi, E. in: Space Vector PWM for A Five-Phase VSI Supplying Two Five-Phase Series-Connected Machines, 12th International Power Electronics and Motion Control Conference, IEEE Publisher (2006).

[7] M. Jones, D. Dujic and E. Levi, in: A Five-Phase Two-Motor Centre-Driven Winder with Series-Connected Motors, 33rd Annual Conference of the IEEE Industrial Electronics Society, IEEE Publisher, (2007)

[8] E. Levi, M. Jones, S.N. Vukosavic, A. Iqbal and H.A. Toliyat, in: Modeling, Control and Experimental Investigation of A Five-Phase Series-Connected Two-Motor Drive with Single Inverter Supply, volume 54 of IEEE Transactions on Industrial Electronics, chapter, 3, IEEE Publisher (2007).

[9] M.J. Duran, F.J. Barrero, S.L. Toral and E. Levi, in: Multi-Dimensional Space Vector Pulse Width Modulation Scheme for Five-Phase Series-Connected Two-Motor Drives, volume 2 of IEEE International Electric Machines \& Drives Conference, IEEE Publisher (2007).

[10] Chen Hung-Chi and Su Chong-Xian, in: Current Control for Single-Inverter-Fed Series-Connected Five-phase PMSMs, IEEE International Symposium on Industrial Electronics (ISIE), IEEE Publisher (2013).

[11] M. Thavot, A. Iqbal, M. Saleh, and A. Kalam, in: Modeling of A Seven-Phase Series-Connected Three-Motor Drive System, 7th IEEE GCC Conference and Exhibition (GCC), IEEE Publisher (2013). 